\title{
Entretenimento: uma mercadoria com valor em alta ${ }^{1}$
}

\author{
Elizara Carolina Marin*
}

\begin{abstract}
Resumo: Este artigo trata do entretenimento como mercadoria valorizada pela sociedade regida pelo capital, pela capacidade que apresenta de incluir a todos, de diferentes idades e gêneros, diferentes estratos sociais, lugares e regiões e, portanto, ser uma fonte geradora de bens econômicos e simbólicos. Busca situar o entretenimento mundialmente, como um componente da cultura do tempo livre, com o poder de absorver pensamentos, corporeidades e estruturar a temporalidade das pessoas.
\end{abstract}

Palavras-chave: Meios de Comunicação de Massa. Marketing. Atividades de Lazer

\section{INTRODUÇÃO}

Este ensaio situa o entretenimento mundialmente, como mercadoria valorizada pela sociedade regida pelo capital, com sua malha de produtos e como um componente da cultura do tempo livre.

Afinal, na sociedade contemporânea, são visíveis os amplos investimentos econômicos na esfera da diversão. Basta caminhar pelas ruas, sintonizar o rádio, acessar a Internet e, especialmente, ligar a televisão para identificar os grandes investimentos em termos de "construção" de equipamentos (como parques, shopping center, bares, casas noturnas, pacotes turísticos, cinemas, hotéis, cruzeiros marítimos), de tecnologias, de produções midiáticas e, em termos de marketing, para estímulo do consumo desse tipo de entretenimento.

$\mathrm{O}$ entretenimento passou a ser uma mercadoria valorizada pela sociedade regida pelo capital. Sociedade que não expropria somente

\footnotetext{
${ }^{1}$ Este artigo é parte da pesquisa desenvolvida no doutorado que resultou na tese: Entretenimento Televisivo: pesquisa do produto e da recepção dos programas de auditório Domingão do Faustão (Rede Globo) e Domingo Legal (SBT), defendida em 2006, em Ciências da Comunicação, na UNISINOS/São Leopoldo, com o apoio e financiamento da CAPES. A pesquisa foi desenvolvida no Brasil e na Espanha em virtude do doutorado-sanduíche na Universidad Autonoma de Barcelona (UAB).

* Doutora em Ciências da Comunicação. Professora do Centro de Educação Física e Desportos da UFSM. Departamento de Desportos Individuais. Santa Maria, RS, Brasil. E-mail: elizaracarol@yahoo.com.br
} 
o tempo de trabalho, mas também o tempo excedente e supostamente livre. A lógica do tempo é dinheiro passou a ser uma referência crucial no sistema de produção e circulação de mercadorias que, como assinala Baudrillard (1995), não cessa no tempo-espaço da fruição humana. Férias, feriados, datas comemorativas, finais de semana e horários após o trabalho passaram a ser disputados no mercado como tempo-mercadoria capaz de gerar lucros.

Nos grandes centros urbanos, o consumo de mercadorias está associado à diversão e a diversão associada ao uso de aparatos de todos os gêneros. Cada vez mais as experiências estão mediadas pelos aparelhos ofertados pelo mercado. Ao que encanta, olha-se com as lentes da câmera fotográfica e da filmadora. Para peregrinar, o homem curva-se ao peso dos aparatos especializados. Para estabelecer relações, acessa a Internet. Para evadir-se, assiste à televisão, a vídeos e joga videogame.

República do entretenimento, indústria do entretenimento, indústria da evasão, gigantes do entretenimento, entretenimento digital, são alguns dos termos utilizados para fazer referência a este que é um dos eixos centrais de investimentos da sociedade atual.

\section{MALHA DE PRODUTOS DE ENTRETENIMENTO}

O setor que mais investe em entretenimento no mundo é o das comunicações, para o que Mattelart A.; Mattelart, M. (2004, p.159) denominam "[...] planeta central do sistema de comunicação". A mídia assume um papel central na produção de entretenimento e consequentemente na apropriação espaciotemporal de uma vasta parcela da população humana.

O relatório Global Entertainment and Media Outlook: 20042008, divulgado pela consultora do PrinceWaterhauseCoopers $(P w C)$, prevê forte expansão da indústria mídia e entretenimento para os próximos anos e significativos investimentos em setores como videojogos, publicidade online, segmentos de acesso pago, distribuição e exibição de cinema, propagação da televisão e da Internet. A previsão é de um crescimento global de $6,3 \%$ para o setor. Para a

Movimento, Porto Alegre, v. 15, n. 02, p. 211-231, abril/junho de 2009. 
América Latina, a previsão é de um aumento maior do que a média (6,5\%), sobretudo no campo da TV por assinatura (cujo crescimento deverá ser de 9,2\%). O que chama a atenção nessas previsões otimistas é o direcionamento de investimentos na mídia para o entretenimento. ${ }^{2}$

Pensar o entretenimento midiático implica situá-lo no contexto da indústria da comunicação que vem apresentando-se em franca expansão e desempenhando um papel-chave na economia mundial. As empresas de comunicação desenvolvem-se internacionalmente para atrair mercado, criar competências e obter lucros. Conforme explica Moraes (1998, p.11), no mapa em que desenha as tendências da comunicação da era global, as empresas de comunicação estão cada vez mais organizadas por conglomerados configurados

[...] como arquipélagos transcontinentais, cujos parâ-metros são a produtividade, a competitividade, a lucratividade e a racionalidade gerencial. Para tanto, buscam conferir escala a seus produtos, por intermédio de alianças e parcerias entre si e com grupos regionais; absorvem firmas menores ou concorrentes, diversificam investimentos em áreas conexas. O resultado não poderia ser outro: uma brutal concentração de atividades nas mãos de poucas companhias (quase todas baseadas nos Estados Unidos da América) e uma aglomeração de patrimônio ativo sem precedentes.

O setor editorial está organizado em aproximadamente dez grandes empresas, sendo que os três com melhor desempenho Bertelsmann, Time Warner e Pearson - controlam 50\% dos negócios em diversos países. O mercado cinematográfico mundial está monopolizado pelos EUA, sendo a empresa Sony quem arrecada maior percentual dos lucros.

Segundo Moraes (1998), na Europa, 50\% dos filmes veiculados pelos canais televisivos são norte-americanos. No Japão, os filmes exportados por Hollywood ocupam, anualmente, 55\% das salas de cinema e, na América Latina, $85 \%$. No setor dos videogames, Sony,

${ }^{2}$ Mercado de Comunicações. [www.fndec.com.br]. Clipping do dia 06.07.2004

Movimento, Porto Alegre, v. 15, n. 02, p. 211-231, abril/junho de 2009. 
Sega e Nintendo centralizam $90 \%$ das vendas mundiais e, na indústria fonográfica, cinco empresas - Poligran, Sony, Warner, BMG Ariola, EMI -, retêm $78 \%$ das vendas mundiais.

O que se percebe nesta breve ilustração da geografia concentradora de alguns dos ramos da indústria do entretenimento é o investimento substancial das empresas, como a Sony, nos diversos setores - informática, telecomunicações e comunicação - formando uma "conjunção de poderes estratégicos", relacionados ao macrocampo multimídia, que Moraes (1998, p.37) denomina infotelecomunicações.

$\mathrm{O}$ entretenimento digital está situado como o setor que vive uma explosão impulsionada pela banda larga na Internet. Os prognósticos da Carly Fiorina, ex-presidente da companhia Helwlett-Packard (HP), é de que o setor de entretenimento digital, até 2007, moveu, no mundo, em torno de 360.000 bilhões de dólares. A HelwlettPackard (HP) destaca-se como uma das empresas mais fortes em escala mundial no setor de computadores, impressoras e hardware empresarial, todavia, no ano de 2004, iniciou investida na área do entretenimento digital, atuando no sentido de convergir às novas tecnologias. O HP Media Center, conforme elucida Sarriegui (2004b), é um produto que congrega as novas tecnologias e permite usufruir de filmes, fotografias digitais, descarga de músicas e Internet.

Uma das apostas das empresas é no entretenimento individual e desenvolvido no espaço doméstico. Dentro deste universo de produtos, destaca-se o videogame. A Associação Espanhola de Distribuidores e Editores de Software de Entretenimento (ADESE) anunciou que a indústria do videogame faturou 800 milhões de euros em 2003, mais do que a indústria do cinema (636 milhões de euros) e da música (550 milhões de euros). Se o videogame era um produto direcionado a crianças e a adolescentes, os indicadores demonstram que atualmente atinge um público de diversas idades e de ambos sexos.

A polêmica em torno dos conteúdos deste produto (inadequados para menores, por serem violentos, sexistas, indutores de abuso a menores, prostituição forçada, tortura, assassinatos...) estende-se e faz com que Universidades e organizações não governamentais solicitem

Movimento, Porto Alegre, v. 15, n. 02, p. 211-231, abril/junho de 2009. 
medidas governamentais para sua regulamentação, conforme é possível identificar em Gosálvez (2005) e Sarriegui (2004a).

Engenheiros, matemáticos, arquitetos, desenhistas e comunicadores produzem uma mescla entre espetáculo, ficção e "realidade" nos recentes investimentos no setor dos videogames e dos parques de diversão. Os denominados docugames, como esclarece Gosálvez (2004), são jogos de videogame com intensa exploração óptico-acústica que apresentam como tema fatos que marcaram o mundo, como o assassinato do presidente norte-americano Kennedy, a Segunda Guerra Mundial, entre outros. Os parques de diversões se voltam para verdadeiras simulações eletrônicas em torno dos limites do universo e do próprio ser humano. No Disneyland Paris, é possível experimentar a missão de ir à Lua e viver o papel de exploronauta, viabilizado por meio de jogos de imagens, de cores, de acústica e produção sensoriomotora. ${ }^{3}$

Ainda que a ampla produção e a expansão das mercadorias para entretenimento tenham sido criadas para o uso no espaço doméstico, elas não estão restritas a ele. O computador portátil, a exemplo do Qosmio, da Toshiba, é um aparato híbrido que integra múltiplas funções - computador, DVD, televisão -, que possibilita, em casa, na rua, no parque, nos deslocamentos e nas férias ter a disposição um aparato para se entreter e estar em companhia.

A estratégia sistêmica empresarial, com franco investimento no setor de entretenimento, amplia os horizontes dos lucros integrando diversas mídias para ofertar uma malha de produtos e suscitar o desejo de outras tantas. Computadores, Internet, câmera fotográfica, câmera de vídeo, televisão, videojogos, telefones móveis e fixos, DVD, CD, rádios e revistas, entre outros mais, unidos para capturar mentes, hábitos e corporeidades não afeitas ou afeitas aos dispositivos analógicos.

A combinação da interação entre as diversas tecnologias infotelecomunicacionais cria novos produtos e serviços no campo do entretenimento, formando redes interdependentes. Como bem observou

\footnotetext{
${ }^{3}$ Esta atração do Disneyland Paris denomina-se Mountain Mission2. Além de engenheiros, arquitetos, desenhistas e músicos da Disney, também colaboraram para fabricar a atração a Agência Espacial Europeia e seus astronautas. [www.spacemountain2.com] Acessado em 22.04.2005

Movimento, Porto Alegre, v. 15, n. 02, p. 211-231, abril/junho de 2009.
} 
o geógrafo Milton Santos (2004), a paisagem dos meios de comunicação que se viabilizam em complementaridade fala ou ilustra o processo produtivo que a engendra. E processo produtivo pensado em sentido amplo diz respeito à produção de mercadorias - mundo dos objetos ou tecnoesfera - e à produção simbólica - mundo das crenças, das ideias, ou a psicoesfera. Portanto, os prognósticos empresariais, no entretenimento midiático de extremo otimismo, derivam dos dados demonstrados pelas estatísticas de produção e venda, mas também como parte de medidas produtoras de sentido, dinamizadoras e impulsionadoras de gostos, ações e decisões.

No mundo da produção, o discurso constitui uma peça fundamental como dispositivo simbólico do modelo econômico e social. O discurso antecipa-se ao "real" com o fim de naturalizar a construção da "realidade", preparando alicerces ao império da publicidade. Como a publicidade não se constrói por si mesma, o que conforma essa teia é o lugar hegemônico que a empresa adquiriu na vida social, sublinha Mattelart (1997), com poder de se articular para criar e para satisfazer necessidades humanas.

Com a hegemonia da empresa, a paisagem humana está cada vez mais artificial e povoada "por sistemas de ações igualmente imbuídos de artificialidade" (SANTOS, 2004, p.63), permeados por mecanismos técnicos produtores de sensações, visando resultados, produtos, objetos, ao invés do desejo pelo processo do agir.

Essa hegemonia, com seus sistemas de objetos e ações, impõem limite às opções humanas, quer pelo acirramento das contradições sociais entre os inforricos e os infopobres (RAMONET, 1997), quer pela necessária mediação dos mecanismos de linguagens organizadas pela esfera da produção no âmbito do entretenimento. Se as novas tecnologias multimídia, organizadas em complementaridade, podem dar vazão a uma nova modalidade de telespectador, supostamente mais ativo, porque interatua, como supõe Monzoncillo (2004), todavia as ações circunscrevem-se entre um rol de práticas já previstas segundo um projeto alheio ao usuário. Ligar e desligar, optar por este ou aquele programa, por esta estratégia ou outra, participar de programas via telefone e Internet pode não significar, na essência,

Movimento, Porto Alegre, v. 15, n. 02, p. 211-231, abril/junho de 2009. 
uma interatuação. Há, portanto, que se questionar o caráter ativo de tais operações.

Não obstante, a generalização do entretenimento não significa democratização dos bens culturais. As desigualdades sociais também reproduzem-se na esfera da diversão. A esfera do tempo livre da diversão não se configura independentemente das demais, defende Sue (1982). A condição econômico-social de uma pessoa, sobretudo, o trabalho que realiza, ou ainda o trabalho negado, condiciona em boa medida as opções no âmbito do tempo livre e o lugar que cada uma ocupa na estrutura social.

Daí que a democratização dos bens culturais ou a liberdade de opção não é uma coisa dada como pretendem os discursos naturalistas, empresariais e de marketing. Assim, as análises sobre o tempo livre e, dentro dele, o entretenimento não podem prescindir dos fatores econômicos, sociais e simbólicos que engendram e determinam os usos e a falta de acesso aos bens.

\section{AinteRNACIONALZZAÇÃO DO ENTRETENIMENTO}

A esfera da diversão desempenha cada vez mais um papel de agente de mudança dos caminhos da sociedade, capaz de gerar um modelo de sociedade não mais alicerçada no desenvolvimento das forças produtivas, mas no desenvolvimento do consumo na esfera do entretenimento. A racionalidade do processo de produção realiza investimento na criação de demandas, não somente por seu valor de uso, mas por meio do fomento ao desejo. Assim, com a publicidade, a relação econômica de demanda e de oferta flexibiliza-se, quando não inverte o processo. Na oferta, o entretenimento é imprescindível, tanto como lógica ${ }^{4}$ para a publicidade quanto como mercadoria lucrativa que tem na gênese um suposto rompimento com o quotidiano.

A configuração do cenário atual de "polarização no entretenimento", para utilizar uma expressão de Mattelart A.; Mattelart, M.

${ }^{4}$ Por lógicas, entende-se as operações racionais de diferentes ordens realizadas pela produção televisiva que definem escolhas e funções dos textos comunicativos, neste caso a publicidade. Dedica-se ao tema: DUARTE, 2004, em especial, no capítulo, "Das lógicas às configurações discursivas", p. 39-52.

Movimento, Porto Alegre, v. 15, n. 02, p. 211-231, abril/junho de 2009. 
(2004, p.159), ${ }^{5}$ tem relação com a valorização do campo cultural por parte do capital. O sistema de comunicação e de cultura de massa impeliu a necessidade de ampliar o acesso aos bens culturais e de consumo, antes restritos às elites, para outros estratos sociais. Resultado, à luz do que desenvolve Habermas (1999), em grande medida, do contexto social de dessacralização e de um prolongado processo de racionalização voltado ao consenso social e em que a linguagem assume papel primordial.

Esse processo de abertura do campo cultural, estreitamente ligado ao processo de mundialização, se materializa sob dois movimentos estratégicos e interligados, ou seja, a desregulamentação e a privatização. O processo de desregulamentação das comunicações nacionais significou, nas palavras de Capparelli e Lima (2004, p.18)

\begin{abstract}
[...] a promoção de reformas nas legislações nacionais que possibilitaram a abertura total ou parcial dos mercados ao capital, nacional ou internacional, e a consequente privatização das empresas estatais de comunicação.
\end{abstract}

Esse movimento se desenvolve de modo distinto em cada região do mundo. No caso do Brasil, com os governos militares (1964-1984), seguido do governo Sarney (1985-1990) e, sobretudo, destacam Capparelli e Lima (2004), no governo Fernando Henrique Cardoso (19952002), muitas foram as normas que garantiram a abertura do mercado de comunicações para o capital estrangeiro, embora, vale lembrar, a propriedade dos meios de comunicação (rádio, TV, imprensa) continue concentrada sob o poder de poucos grupos. O Estado, portanto, atuou como um ator fundamental na desregulamentação que permitiu privatizações (telecomunicações), entrada do capital estrangeiro (mídia televisiva aberta e fechada, telefonia fixa e móvel) e abertura à importação de mercadorias da indústria cultural estrangeira.

Na mídia televisiva há, em geral, nos canais comerciais, baixos percentuais de conteúdos informativos e educativos - e dessa parcela

\footnotetext{
${ }^{5}$ Ana Paula Castellani, na obra de Mattelart A.; Mattelart, M. (2004) Pensar as mídias, assim traduziu "polarização da diversão". Por entender que o termo entretenimento seja mais adequado para o que propõem os autores, sempre que houver citação desta obra, o termo diversão será substituído por entretenimento.

Movimento, Porto Alegre, v. 15, n. 02, p. 211-231, abril/junho de 2009.
} 
muitos são veiculados (propositadamente?) em franjas horárias inacessíveis a uma larga faixa de público -, mas, com amplos espaços para o entretenimento. E no canal público, parcos investimentos em recursos humanos e técnicos, ainda que com interesse no educativo e cultural.

No caso da Europa, nas últimas décadas do século XX, com a desregulamentação decorre uma profunda crise no modelo de televisão pública, com suas características de território audiovisual nacional e protegido do espaço comercial, visível nos anos setenta e, de modo mais agudo, nos anos oitenta. Nesse contexto de abertura, de comercialização e de internacionalização de produtos audiovisuais, o entretenimento figura como o principal produto. Para Mattelart A; Mattelart, M. (2004, p.159), autores que se preocuparam em estabelecer relações entre mídias e entretenimento argumentam que "é a partir do entretenimento que as televisões nacionais se internacionalizam, com a informação, o cultural e o educativo constituindo bolsões de resistência".

Neste contexto, são ilustrativos os dados da pesquisa realizada por Bustamante e Giu (1988), sobre a televisão na Europa, mais especificamente na Espanha, na década de 1980. Os autores constataram que o aumento dos índices da programação de entretenimento se dá na proporção do aumento dos canais comerciais, mas, em contrapartida, fica menor o índice de programas culturais. Corroboram com esses resultados, como ilustram os autores, os dados divulgados em 1986, pelo Estudio Horizons Media, ao demonstrarem que sobre 3.500 horas de programação de canais televisivos, em 13 países europeus, $86 \%$ eram de entretenimento, sendo que, em alguns casos, alcançavam até $90 \%$.

A política de desregulamentação e de privatização gerou entre os diferentes canais televisivos - públicos e privados, abertos e fechados - uma sinergia competitiva sem precedente. Derivada da necessidade de desenvolver estratégias para alcançar audiências, reduzir custos, estender horários de emissão diária, o entretenimento foi erigido como a função que coaduna essas características. Todavia, não se restringe ao campo das mídias.

Movimento, Porto Alegre, v. 15, n. 02, p. 211-231, abril/junho de 2009. 
Nos diferentes campos sociais, o entretenimento passou a ser uma linguagem aceita e necessária, quer em sua forma material quer em sua forma simbólica, pois, vale dizer, não há manifestação material que não tenha conotação simbólica. Conforme argumenta Esteves (1998), a dimensão material e objetiva dos campos sociais é a dimensão mais perceptível, mas, a mais essencial, é de ordem simbólica e constitui os processos que estão na própria gênese dos campos.

No campo da educação, o entretenimento mostra-se cada vez mais presente nas estratégias para tornar mais divertido o processo ensino-aprendizagem, seja por meio da apropriação das novas tecnologias ou da organização dos espaços de ensino. O problema que se coloca, e que difere da análise de muitos autores, não está no uso de uma abordagem lúdica em ensino-aprendizagem, mas na ênfase "educacional" que passa a privilegiar o produto (de mercado) em função do resultado, ao invés dos processos de vivência; e as técnicas e os aparatos, ao invés da gestação de pensamentos.

No âmbito do ensino superior, está cada dia mais comum encontrar campi universitários organizados nos moldes do shopping center. Se a universidade poderia ser unidade espaciotemporal de vivências de outros valores, ao contrário, sua arquitetura denuncia a sedução que o entretenimento tece e lhe exerce. Resultado das teias do capitalismo cuja tendência é a de transformar tudo quanto toca em mercadoria, como diria Ramonet (1997).

No campo religioso, muitos exemplos podem ser enumerados. No âmbito nacional, vale atenção a figura paradigmática assumida por Padre Marcelo Rossi, em especial na década de 1990; um padre jovem, alto, olhos azuis, sorriso constante no rosto, desenvoltura e energia de ex-professor de aeróbica e, por tais qualidades, com poder de agregar multidões em suas celebrações-show e nas aparições nos programas de auditório dominicais da TV aberta brasileira, ao entoar a aeróbica de Deus, ritmada por palmas e gestualidades. Nas missas, um padre-show, nos programas de auditório, uma celebridade disputada, cuja presença atrai audiência. A atuação do Padre Marcelo constitui, por um lado, o reconhecimento da ineficiência dos métodos tradicionais de evangelização e, por outro lado, incorpora a lógica da sociedade midiatizada.

Movimento, Porto Alegre, v. 15, n. 02, p. 211-231, abril/junho de 2009. 
No jogo de forças entre os diferentes campos sociais que formam redes de diálogos, interesses, interferências, recuos e interdependências, muitas das estratégias utilizadas derivam do campo da mídia. O campo midiático passa a ser assumido como uma instância de mediação social, em que a linguagem e os conteúdos que entretêm, nas suas diversas versões - show, espetáculo, cores, ritmos, sonoridades, objetos - passa a ser naturalizado. Tal naturalização afasta os processos racionais e, assim, a leitura dos produtos passa a ser realizada pelo plano subjetivo. O risco pode ser traduzido em, diante daquilo que está sob nossos olhos e nos diversos âmbitos da vida, passar a se perceber o entretenimento como elemento natural e não como produto, e, ao mesmo tempo, como processo, resultante do modo de produção capitalista. Com a polarização no entretenimento, como observam Mattelart A. Mattelart, M. (2004, p.158),

[...] o que tende a se perder não é apenas a ideia de que a mídia assume em toda sociedade outras funções além da de divertir, mas também uma outra ideia: a de que o entretenimento não tem simplesmente o papel de distrair.

\section{ENTRETENIMENTO E EsTADOS UNIDOS}

Nenhum país exerceu ou exerce tanta influência no campo do entretenimento como os Estados Unidos. Se, atualmente, encontra-se em crise em diversos níveis (ideológico, econômico, tecnológico e cultural), no campo da indústria do entretenimento, com seus filmes, seriados, musicais, formatos televisivos, videojogos, parques de diversão, continuam como grande força econômica, expressiva e comunicativa.

No mundo contemporâneo, a força de uma nação que, ademais de estar relacionada aos atributos militares, às redes econômicas, os quais são capazes de liderar, dos fluxos financeiros, dos intercâmbios comerciais, deriva da supremacia das inovações tecnológicas e comunicacionais. Neste setor, o país que exerce hegemonia por seu poder de produção e irradiação de tecnologia, mídias, produção audiovisual, modas e comportamentos são os Estados Unidos, esclarece Ramonet (1997).

Movimento, Porto Alegre, v. 15, n. 02, p. 211-231, abril/junho de 2009. 
Seu poder de produção de tecnologias comunicacionais e audiovisuais está respaldado pelo desenvolvimento de um saber instrumental e pragmático voltado para elaborações de estratégias para resolver operações técnicas, militares, comerciais e sociais. Trata-se do amplo desenvolvimento de conhecimentos que visam à legitimação de estratégias e modelos sistêmicos empresariais que corroboram para fortalecer a ideia da supremacia do seu poder como nação - perante as outras nações do mundo - e do poder das técnicas em detrimento da política. A ciência, a técnica e a teoria do mercado único são os agentes que protagonizam a dominação norte-americana.

Vale ressaltar que o que está em pauta não é a crença na teoria da colonização cultural estado-unidense, ou da americanização do mundo, termo este, inclusive, que merece ser revisto, pois afinal o continente americano, em sua totalidade, engloba muitos outros países além dos Estados Unidos, inclusive o Brasil. Se a hegemonia norteamericana é evidente, também é evidente a coexistência de outras formas de manifestações culturais e sociais. No mesmo curso em que ocorre a homogeneização, desenvolve-se, no contato com outras formas de vida e trabalho, a contradição, a fragmentação, as diversidades. Como formulou Ianni (1998, p.89), "“[...] o mesmo vasto processo de globalização do mundo é sempre um vasto processo de pluralização dos mundos".

A inegável expansão da produção e penetração midiática norteamericana não impede que as culturas locais realizem dinâmicas de reconstrução das fórmulas, dando feições locais a um produto global. Esse processo de apropriação do global pelo local, denominado por Buonanno (1999), a partir da leitura de Robertson, de indigenização, constrói-se sob um referencial que engloba termos como apropriação, hibridização, heterogeneidade. Dentro desse paradigma, o local não se resume a uma mostra em miniatura da imposição do global, mas por sua articulação com o global.

Se, na atualidade, a oferta de ficção norte-americana aumenta na programação de canais televisivos da TV aberta de países com mercado emergente, entre os quais situam-se os países do Leste europeu (Polônia, Eslováquia etc.) e, se na programação televisiva europeia

Movimento, Porto Alegre, v. 15, n. 02, p. 211-231, abril/junho de 2009. 
apresenta altos percentuais de horas - uma média de 50\% -, com algumas diferenças entre os vários países, ${ }^{6} \mathrm{o}$ Observatório Audiovisual Europeu, organismo de serviço público ligado ao Conselho da Europa, registra que eles ocupam cada vez menos espaço na franja horária considerada prime time.

Ademais, o fortalecimento de indústrias televisivas nacionais configura em novos horizontes. No Brasil, a Rede Globo é um exemplo. Atualmente, ela produz em torno de $73,71 \%$ da programação que veicula e mantém sua capacidade para exportar. A Holanda é outro país que tem se destacado na produção e na exportação do formato reality shows, para o qual Buonanno $(2005)^{7}$ atribui como exemplo singular da influência do entretenimento europeu no mundo. Exemplo que faz a autora crer que a produção de entretenimento está começando a se tornar polissêntrico, ou seja, não há mais um centro que distribui para as periferias. Nesta mesma perspectiva, García Avilés e Leon (2002) destacam a atividade de produtoras europeias, tais como Celador, Endemol, Pearson, Action Time, dedicadas ao desenvolvimento de entretenimento que tem conseguido entrar no mercado norte-americano, invertendo o sentido tradicional do fluxo comercial.

Entretanto, é iniludível a presença de produtos e de matrizes norte-americanas na oferta televisiva de quase todos os países ocidentais. Muito provavelmente não há um jovem ocidental que não tenha assistido a uma série ou a um filme norte-americano. O mesmo não se pode inferir sobre o caso brasileiro, ainda que este represente a quarta maior rede de televisão do mundo. Os game show, ${ }^{8}$ os quis show, ${ }^{9}$ os concursos, os talk show, ${ }^{10}$ por exemplo, são referências estado-unidenses importantes que povoaram e povoam a programação

\footnotetext{
${ }^{6}$ De sua parte, os Estados Unidos atuam como um país protecionista e, ao lado da China e da Coreia do Norte, importam do mercado estrangeiro menos de $2 \%$ do que consomem em audiovisual. (RAMONET, 1997)

${ }^{7}$ Interlocução (gravada e transcrita) realizada com Buonanno, no dia 16.05.2005, no "Osservatorio sulla Fiction Italiana", Roma, Itália. Mais dados disponíveis em: <http://www.campo-ofi.it>

${ }^{8}$ Trata-se de diferentes tipos de provas competitivas de destreza física (jogos), reconfigurados pela linguagem televisiva para a formação de um show.

${ }^{9}$ Configura-se por um gênero desenvolvido com provas de pergunta e resposta de conhecimentos gerais

${ }^{10}$ Trata-se de um gênero, em resumo, que se apoia na figura do apresentador e se articula em torno de história de vidas narradas pelos próprios protagonistas e contemplam a presença de plateia no estúdio.
}

Movimento, Porto Alegre, v. 15, n. 02, p. 211-231, abril/junho de 2009. 
televisiva da maioria dos canais televisivos existentes no mundo. E, no caso de algumas redes, tal como o Sistema Brasileiro de Televisão (SBT), esses formatos estruturam e compõem a história da rede.

Para discutir as razões que levam à grande circulação e ao consumo de produtos de entretenimento estado-unidense por outros países, Buonanno (1999) argumenta que a conveniência econômica é o primeiro fator que se deve considerar. Adquirir é mais simples e dá resultados imediatos se comparados aos gastos de tempo e recursos para produzir. Relacionado a esse fator, está a natureza serial dos produtos que, ao disponibilizar grande volume quantitativo, assegura a cobertura de amplos espaços de programação. Constituem-se também em produtos que, por serem testados, oferecem uma certa garantia de aprovação.

Os aspectos econômicos e empresariais ou de custo-benefício são importantes para a análise; todavia, não alcança a compreensão, por exemplo, na esfera da recepção, da relação que se estabelece entre o público e esses produtos garantindo a audiência e, consequentemente, sua hegemonia. A intenção não é aprofundar o tema, mas situar que a leitura somente pela lógica econômica não permite, à luz do que propõe Martín-Barbero (1992), compreender o que leva os receptores a extraírem prazer e a se comoverem com os produtos da cultura midiática.

E, neste âmbito, os aspectos ligados aos conteúdos, aos ritmos, às imagens, à estética dos produtos, já expostos pelo crítico de arte Postman (1991), na década de 1980, são fundamentais. Em sua organização, a produção audiovisual estado-unidense estrutura-se como espetáculo, com uma grande variedade de temas que, simples em sua estrutura, não requerem grande exercício mental e conhecimento para a compreensão e são dirigidas, sobretudo, à evasão e à satisfação emocional, quer seja pelos conteúdos, imagens, musicais, ou pelo somatório de todos.

A análise também não pode prescindir de pensar os contextos e ênfases sociais e históricos das diferentes regiões do mundo. Nos Estados Unidos, os meios de comunicação, desde seu princípio, foram controlados pelo mercado. Além disso, é um país que agregou condições

Movimento, Porto Alegre, v. 15, n. 02, p. 211-231, abril/junho de 2009. 
para constituição de competências técnicas, científicas e produtivas no campo dos audiovisuais, desenvolvidas e organizadas por uma racionalidade - que visa a aumentar a eficácia dessas competências -, planificada com o horizonte no futuro e fortalecida pela âncora legitimadora da cientificidade - já que, supostamente, à ciência compete a construção do saber e não a construção de impérios econômicos.

De modo diferente, na Europa Ocidental, o Estado adotou a gestão do meio televisivo com uma produção própria que salvaguardava e desenvolvia a cultura nacional e a protegia das influências comerciais. Os princípios que regiam a produção eram coerentes com a política do Estado de bem-estar social, privilegiando os aspectos informativos e culturais. Durante as primeiras décadas da existência da televisão até os anos setenta, quando se fazia visível o processo político-social de abertura, a Europa não havia desenvolvido competências na produção audiovisual com a função de entretenimento comercial. (BUSTAMANTE; GIU, 1988; MATTELART, A.; MATTELART, M.; 2004)

Dados atuais do Observatório Audiovisual Europeu registram: 1- a circulação de obras europeias, tanto de ficção televisiva como cinematográfica, entre países europeus segue sendo baixa e, em alguns países, como o Reino Unido, quase nula; 2- desde o ano 2000 , o volume de horas de ficção importado dos Estados Unidos pelos principais canais europeus está diminuindo, todavia esta redução está compensada por emissões de coproduções transatlânticas e coproduções internacionais; a programação dos canais especializados abriu novos espaços à programação norte-americana e inflacionou os custos para aquisição dos direitos. (LANGE, 2003)

A análise realizada por Lange (2003), no contexto atual de um continente que realiza esforços políticos para a criação de um mercado audiovisual próprio, não é tão positiva. Para o autor, a emissão e a circulação de programas europeus seguem sendo baixas e ameaçam a diversidade cultural local.

Enquanto os Estados Unidos desenvolvem uma política de livre circulação para os produtos audiovisuais e o encontro do Acordo Geral sobre Tarifas e Comércio (GATT), em Bruxelas, em 1993, nesse

Movimento, Porto Alegre, v. 15, n. 02, p. 211-231, abril/junho de 2009. 
sentido foi representativo, ${ }^{11}$ os europeus buscam proteger seus meios de comunicação. As divergências derivam na análise de García Canclini (2001, p.180), das distintas maneiras de conceber a cultura:

"[...] para os EUA, os entretenimentos devem ser tratados como um negócio: não só porque o são de fato, mas porque constituem para esse país a segunda fonte de rendimento entre todas as suas exportações, depois da indústria aeroespacial".

Em importante estudo sobre a indústria cultural brasileira, o antropólogo Renato Ortiz (2001, p.199) observa, a partir do estudo sobre o fluxo da programação televisiva mundial, realizado pela UNESCO, em 1973, que a América Latina foi considerada "zona de influência norte-americana", revelando um percentual que chegou a atingir $84 \%$ em determinados países.

O caso brasileiro, a relação que se estabelece entre Estado e televisão, em virtude das intervenções dos governos, facilitou a abertura do mercado televisivo para a produção estrangeira. E como alude Ortiz (2001), “[...] durante um certo período da história da televisão brasileira, a presença da produção estrangeira é considerável". Em meados da década de 1950, quando o segmento acabava de ser inaugurado no Brasil, diante da fragilidade tecnológica e financeira das empresas brasileiras e, por outro, da expansão da indústria norte-americana, tornou-se mais rentável importar programas do que produzir. Os anos sessenta demonstram percentuais significativos de programas importados em curva crescente nas diferentes emissoras existentes (Excelsior, Record, Tupi, Rede Globo). Na década de 1970, mais precisamente em 1978, os dados da pesquisa de Caparelli (1982) demonstram que se conservam os níveis elevados de programação de origem estrangeira, mais precisamente estado-unidense, atingindo $48 \%$. Essa realidade decorre, na visão de Ortiz, (2001), da fragilidade das instituições existentes, tornando-se necessária a importação de tecnologias, produtos e recursos humanos de fora do país. Corresponde, como

${ }^{11} \mathrm{O}$ encontro do GATT (General Agreement on Tariffs and Trade) reuniu 117 países e constituiuse pela aprovação de ampla liberalização econômica com desacordos significativos na área dos audiovisuais.

Movimento, Porto Alegre, v. 15, n. 02, p. 211-231, abril/junho de 2009. 
considera esse autor, a um período de "incipiência da moderna sociedade brasileira" e de modo inverso, de "[...] expansionismo americano que fortalece sua política de dominação". (ORTIZ, 2001, p.191-192)

Porém, na década de 1970, em consonância com a elevada importação, esboçava-se um movimento de produção de programação nacional por meio das telenovelas. No percurso de consolidação, os anos 1990 anunciam um novo cenário, em que a produção aumenta significativamente nas diferentes emissoras, especialmente na Rede Globo.

É importante lembrar que as marcas estado-unidenses não se fazem presentes somente na forma de produto acabado (como filmes, séries), mas, nos gêneros, nos formatos, nas técnicas, nos modos de produzir, de organizar os enunciados e de realizar a enunciação. Marcas que nem sempre as estatísticas podem captar.

Essa contextualização assinala que, nas primeiras décadas de desenvolvimento da televisão, tanto a Europa quanto a América Latina, guardadas as diferenças históricas, sociais e políticas, não haviam desenvolvido políticas e competências de produção audiovisual com a função de entreter, levando-os a se abastecerem no país que se consolidava como a "República do entretenimento", para utilizar o termo do jornalista e crítico cultural Gabler (2000, p.37).

De acordo com o que propõe Gabler (2000), no campo do entretenimento midiático, os Estados Unidos apresentam-se como o grande produtor e propulsor no mundo ocidental. Na história dessa nação, o conflito de poder entre o erudito e o popular, o intelectual e o senso comum, o institucional e o popular, e entre as diferentes classes sociais, a vitória da democracia no século XIX abriu um processo de desenvolvimento da cultura popular, do livre mercado, sendo que "[...] o entretenimento passou a ser o equivalente cultural da política igualitária" (GABLER, 2000, p.36).

A intenção não é desenvolver miradas tautológicas, mas ignorar o poder de produção e de irradiação de entretenimento estado-unidense no mundo não deixa de ser uma forma de cerrar o olhar ao que povoa quotidianamente os sentidos.

Movimento, Porto Alegre, v. 15, n. 02, p. 211-231, abril/junho de 2009. 


\section{CONSIDERAÇÕES FINAIS}

À luz do exposto, faz-se necessário assinalar, que o entretenimento tornou-se uma mercadoria com valor em alta, pois responde a uma necessidade humana, qual seja, a de diversão; no entanto, responde também aos interesses das instituições e do próprio sistema capitalista. As necessidades humanas de lazer, de diversão, entre outras, são funcionalizadas e reproduzidas pelo comércio.

Além disso, o entretenimento caracteriza-se, como explica Gabler (2000), por não fazer exigência de público, ao contrário, por englobar a todos e atuar com os sentidos, com as emoções, para além do trabalho da razão. Na esteira dos argumentos deste autor, a etimologia latina da palavra expressa o quanto o elemento sensório no entretenimento é central: vem de inter (entre) e tenere (ter), ou seja, ter entre. E em todas as suas variações - via televisão, cinema, internet, jogos eletrônicos, entre outros -, o entretenimento objetiva apreender a atenção, o tempo e a consciência das pessoas.

Assim, o entretenimento assumiu importância crucial pela capacidade que apresenta de incluir a todos, de diferentes idades e gêneros, diferentes estratos sociais, lugares e regiões do mundo e, portanto, ser uma fonte geradora de bens econômicos e simbólicos.

Em última instância, o entretenimento não é uma categoria neutra. É um componente da cultura do tempo livre, numa sociedade sob modelo capitalista, com o poder de absorver pensamentos, corporeidades e estruturar a temporalidade das pessoas. O mercado instrumentaliza o tempo livre e oferece produtos com poder de agregar consumidores e se dinamizar nas mais diferentes formas de fruição e nos diferentes espaços de circulação humana.

Movimento, Porto Alegre, v. 15, n. 02, p. 211-231, abril/junho de 2009. 


\begin{abstract}
Entertainment: merchandise at a high stock price Abstract: The present paper is related to entertainment as merchandise valued by a society ruled by the capitalism, because of this ability of including everyone, of different ages and gender, different social position, places and regions and, therefore, to be a generating source of economic and symbolic goods. It also has as objective to situate the entertainment globally, as a component of the spare time culture, with the power to absorb thoughts, body languages and to structure people's temporariness.

Keywords: Mass Media. Marketing. Leisure Activities
\end{abstract}

Entretenimiento: la mercancía a un precio accionario alto

Resumen: El presente artículo se relaciona a la función del entretenimiento como mercancía valorada por una sociedad gobernada por el capitalismo, debido a esta habilidad de incluir a todos, de edades diferentes y género, posición social diferente, lugares y regiones $\mathrm{y}$, por consiguiente, para ser una fuente generadora de género económico y simbólico. También tiene como el objetivo situar la función globalmente, como un componente de la cultura de tiempo libre, con el poder para absorber los pensamientos, corporalidades y para estructurar la temporalidad de las personas.

Palabras clave: Medios de Comunicación de Masas.

Mercadeo. Actividades Recreativas

\title{
REFERÊNCIAS
}

BAUDRILLARD, J. A sociedade de consumo. Lisboa: Edições 70, 1995.

BUONANNO, M. El drama televisivo: identidad y contenidos sociales. Barcelona: Gedisa, 1999.

BUSTAMANTE, E.; GIU, I. Televisión: desequilíbrios en cadena. In: BUSTAMANTE, Enrique; ZALLO, R. (Org.). Las industrias culturales en España: grupos multimidia y transnacionales. Madrid: Akal, 1988. p. 109-162.

CAPPARELLI, S. Televisão e capitalismo no Brasil. Porto Alegre: LP\&M, 1982.

CAPPARELLI, S.; LIMA, V. A. de. Comunicação e televisão: desafios da pósglobalização. São Paulo: Hacker, 2004.

DUARTE, El. B. Televisão: ensaios metodológicos. Porto Alegre: Sulina, 2004.

Movimento, Porto Alegre, v. 15, n. 02, p. 211-231, abril/junho de 2009. 
ESTEVES, J. P.. A ética da comunicação e os media modernos. Lisboa: Dinalivros, 1998.

GABLER, N. Vida - O Filme: como o entretenimento conquistou a realidade. São Paulo: Companhia da Letras, 2000.

GARCÍA AVILÉS, J. A.; LEÓN, Bienvenido. Análisis de la diversidad cultural em los programas de mayor audiência (1995-2000) y de los espacios culturales de calidad em las televisiones europeas. In: GARCÍA AVILÉS, José Alberto; LEÓN, Bienvenido. Revista Comunicación y sociedad, Pamplona, v. 15, n.1, p. 69-99, jun. 2002.

GARCÍA CANCLINI, N. Consumidores e cidadãos. Rio de Janeiro: Editora da UFRJ, 2001.

GOSÁLVEZ, P. Sexo e violencia para todos los públicos. El País, Madrid, p.22, 09 jan., 2005.

Esto no es un juego. El País, Madrid, p.23, 03 dez. 2004.

HABERMAS, J. Teoria da ação comunicativa I. Madrid: Taurus, 1999.

IANNI, O. Teorias da globalização. Rio de Janeiro: Civilização Brasileira, 1998.

LANGE, A. La circulación europea de programas de televisión sigue siendo baja. Revista Telos, Madrid, n.55, p.17-22, abr/jun., 2003.

MARTÍN-BARBERO, J. Prefácio. In: LOPES, Maria I. V. L. (Org.) Vivendo com a telenovela: mediações, recepção, teleficcionalidade. São Paulo: Summus, 2002. p. 11-18.

MATTELART, A.; MATTELART, M. O carnaval das imagens. São Paulo: Brasiliense, 1998.

Pensar as mídias. São Paulo: Loyola, 2004.

MATTELART, A. Utopía y realidades del vínculo global. Para una crítica del tecnoglobalismo. Revista Diálogos de la Comunicación, Lima, n.50, p.8-24, 1997.

MONZONCILLO, J. M. Á. El futuro del ocio en el hogar. Madrid: Fundación Autor, 2004.

MORAES, D. Planeta mídia: tendências da comunicação na era global. Campo Grande: Letra Livre, 1998

ORTIZ, Renato. A moderna tradição brasileira: cultura brasileira e indústria cultural. São Paulo: Brasiliense, 2001.

POSTMAN, Neil. Divertir-se hasta morir: el discurso público en la era del "show business". Barcelona: Tempestad de Ideas, 1991. v. 1

RAMONET, I. Un mundo sin rumbo: crisis de fin de siglo. Madrid: Debate, 1997.

Movimento, Porto Alegre, v. 15, n. 02, p. 211-231, abril/junho de 2009. 
SANTOS, M. A natureza do espaço: técnica e tempo. Razão e Emoção. São Paulo: Editora da Universidade de São Paulo, 2004.

SUE, R. El ocio. México: Fondo de Cultura Económica, 1982.

SARRIEGUI, J. El videojogo se ve envuelto en varias polémicas trás actos violentos. EI País. Madrid, p.17, 02 ago., 2004a

Nos movemos ao ócio digital. El País. Madrid. p.20, 03 out., 2004b.

Recebido em: 07/03/2008

Aprovado em: 16/02/2009

Movimento, Porto Alegre, v. 15, n. 02, p. 211-231, abril/junho de 2009. 